\title{
VEGF-A/VEGFR-2 Signaling Leading to cAMP Response Element-Binding Protein Phosphorylation Is a Shared Pathway Underlying the Protective Effect of Preconditioning on Neurons and Endothelial Cells
}

\author{
Hsueh-Te Lee, ${ }^{1}$ Ying-Chao Chang, ${ }^{4}$ Yi-Fang Tu, ${ }^{2,3}$ and Chao-Ching Huang ${ }^{1,2}$ \\ ${ }^{1}$ Department of Pediatrics, ${ }^{2}$ Institute of Clinical Medicine, and ${ }^{3}$ Department of Emergency Medicine, National Cheng Kung University Hospital, Tainan \\ 70428, Taiwan, and ${ }^{4}$ Department of Pediatrics, Chang Gung Memorial Hospital-Kaohsiung Medical Center, Chang Gung University College of Medicine, \\ Kaohsiung 83301, Taiwan
}

\begin{abstract}
Preconditioning protects endothelial cells as well as neurons from ischemic injury. In 7-d-old rat pups, ligating the carotid artery $1 \mathrm{~h}$ before hypoxia damaged the ipsilateral cerebral hemisphere; in contrast, ligating the artery 24 h before hypoxia provided complete neuroprotection. The protective effect of the $24 \mathrm{~h}$ artery ligation preconditioning model requires the activation of cAMP response element-binding protein (CREB). We tested the hypothesis that vascular endothelial growth factor (VEGF)-A/VEGF receptor-2 (VEGFR-2) signaling that leads to CREB activation is the shared pathway underlying the protective effect of preconditioning in neurons and endothelial cells. VEGF-A, VEGFR-1, or VEGFR-2 was inhibited by antisense oligodeoxynucleotides (ODNs) in vivo and by a VEGF-A neutralizing antibody or VEGFR-2 inhibitor in vitro. CREB phosphorylation (pCREB) and VEGF-A and VEGFR-2 expression were increased and colocalized in vascular endothelial cells and neurons in the ipsilateral cerebral cortex $24 \mathrm{~h}$ after ligation. The antisense ODN blockades of VEGF-A and VEGFR-2 decreased pCREB and reduced the protection of $24 \mathrm{~h}$ ligation preconditioning. Furthermore, oxygenglucose deprivation (OGD) preconditioning upregulated VEGF-A, VEGFR-2, and pCREB levels and protected immortalized H19-7 neuronal cells and b.End 3 vascular endothelial cells against $24 \mathrm{~h}$ OGD cell death. Blocking VEGF-A or VEGFR-2 reduced CREB activation and the effects of OGD preconditioning in neuronal cells and endothelial cells. Transfecting a serine-133 phosphorylation mutant CREB also inhibited the protective effect of OGD preconditioning. We conclude that VEGF-A/VEGFR-2 signaling leading to CREB phosphorylation is the shared pathway underlying the preconditioning-induced protective effect in neurons and vascular endothelial cells in the developing brain.
\end{abstract}

\section{Introduction}

Hypoxic-ischemic (HI) encephalopathy is a major cause of neonatal mortality and neurological disabilities in childhood (Huang et al., 1999; Ferriero, 2004). A new approach to studying treatment for neonatal HI encephalopathy is investigating states of tolerance (Chang and Huang, 2006; Gidday, 2006). Tolerance is attained by preconditioning tissue to sublethal stress, which causes the tissue to augment endogenous defense mechanisms and become more tolerant of subsequent lethal insult. Although neurons are the cellular target of preconditioning, ischemic tolerance occurring on vascular cells also contributes greatly to neuroprotection (Gidday, 2006; Gustavsson et al., 2007; Kunz et al.,

Received Nov. 14, 2008; revised Dec. 29, 2008; accepted Feb. 24, 2009.

This study was supported by Taiwan National Health Research Institute Grant NHRI-EX94,95,96-9414NI, National Science Counsel Grants 94-2314-B-006-053 and 95-2314-B-006-099, and the Center for Gene Regulation and Signal Transduction Research, National Cheng Kung University. We thank Chien-Jung Ho for her technical assistance in the animal preparations and Bill Franke for English manuscript editing.

Correspondence should be addressed to Dr. Chao-Ching Huang, Department of Pediatrics, National Cheng Kung University Hospital, 138 Sheng-Li Road, Tainan City 704, Taiwan. E-mail: huangped@mail.ncku.edu.tw. DOI:10.1523/JNEUROSCI.5497-08.2009

Copyright $\odot 2009$ Society for Neuroscience $\quad 0270-6474 / 09 / 294356-13 \$ 15.00 / 0$
2007). Studies have suggested that preconditioning improves microvascular perfusion and protects cerebral blood vessels from ischemia (Lee et al., 2004; Hoyte et al., 2006; Kunz et al., 2007). The protective mechanisms of preconditioning in endothelial cells include upregulating Akt-dependent survivin (Zhang et al., 2007) and downregulating intercellular adhesion molecule-1 (Beauchamp et al., 1999; Andjelkovic et al., 2003). Although hypoxic preconditioning upregulated vascular genes in the cerebral cortex (Gustavsson et al., 2007), the cell type that had increased vascular gene expression was unknown. More importantly, very few studies have examined whether there is a shared signaling pathway that underlies preconditioning-induced protection in neurons and vascular endothelial cells.

In 7-d-old rat pups, ligating the carotid artery $1 \mathrm{~h}$ before hypoxia damaged the ipsilateral cerebral hemisphere; in contrast, ligating the artery $24 \mathrm{~h}$ before hypoxia provided complete neuroprotection (Lee et al., 2004). The protective effect of the $24 \mathrm{~h}$ artery ligation preconditioning required the activation of cAMP response element-binding protein (CREB) (Lee et al., 2004), a transcription factor implicated in synaptic plasticity, memory, and survival of the nervous system (Lonze and Ginty, 2002; 
Ratan, 2004). However, it remains to be determined whether this $24 \mathrm{~h}$ artery ligation preconditioning affects CREB activation in neurons and vascular endothelial cells. If so, then, the preconditioning-activated transducer and upstream pathway that leads to CREB activation in neurons and endothelial cells warrants investigation because the molecules that protect both vessels and neurons will be attractive therapeutic targets (Zacchigna et al., 2008).

Vessels and nerves guide each other to their target during development. This neuronal and vascular crosstalk includes the use of common signals, such as vascular endothelial growth factor (VEGF)-A, to determine the fate of neurons and vascular endothelial cells (Zacchigna et al., 2008). Recent insights into the role of VEGF-A in a variety of neurological disorders suggest that VEGF-A and its downstream effectors may be promising therapeutic targets in these diseases (Zhang et al., 2000; Yang et al., 2002; Rosenstein et al., 2003; Cao et al., 2004; Greenberg and Jin, 2005). Because VEGF-A is highly expressed in neurons and vessels throughout the early postnatal period (Storkebaum et al., 2004), VEGF-A may be a major protector through its dual neuronal and vascular effects in the developing brain.

VEGF-A binds to two cell-surface tyrosine kinase receptors, VEGFR-1 and VEGFR-2, which activate several downstream pathways (Ferrara et al., 2003). An in vitro hypoxic preconditioning study (Wick et al., 2002) showed the requirement for VEGFA/VEGFR-2 activation for neuronal survival. The VEGF/ VEGFR-2 pathway was also involved in the neuroprotection of hypoxic preconditioning in a neonatal murine model of excitotoxic brain injury (Laudenbach et al., 2007). However, the exact cell types that are involved in the protective effects of VEGF/ VEGFR-2 signaling during preconditioning remain undetermined. Whether VEGF-A/VEGFR-2 induced by preconditioning leads to CREB activation in neurons and endothelial cells is unknown. It also remains to be determined whether VEGF-A/ VEGFR-2 signaling leading to CREB activation is the shared pathway underlying the protective effect of preconditioning in neurons and vascular endothelial cells in the developing brain.

\section{Materials and Methods}

Animals used. This study was approved by the Animal Care Committee of National Cheng Kung University. Ten to 12 Sprague Dawley male rat pups per dam were used and housed with a $12 \mathrm{~h}$ light/dark schedule in a temperature- and humidity-controlled colony room. The pups were housed with their dams until weaning on postpartum day 21 (P21), and then they were housed in groups of four to five per cage. In P7 rat pups, unilateral common carotid-artery ligation, followed $1 \mathrm{~h}$ later by $8 \%$ oxygen hypoxia for $2 \mathrm{~h}$, produced selective damage in the hemisphere ipsilateral to the artery occlusion; this damage resembled $\mathrm{HI}$ damage to the human neonatal brain.

A preconditioning model by $24 \mathrm{~h}$ carotid-artery ligation in neonatal rats. The littermates were divided into three groups: the preconditioned group (right carotid artery was ligated $24 \mathrm{~h}$ before exposing them to $2 \mathrm{~h}$ of $8 \%$ oxygen hypoxia), the non-preconditioned group (right carotid artery ligated $1 \mathrm{~h}$ before $2 \mathrm{~h}$ of $8 \%$ oxygen hypoxia), and the sham control group (the neck was given an incision, but neither was the carotid artery ligated nor was the rat pup subjected to hypoxia), as described previously (Lee et al., 2004). The preconditioned-and non-preconditioned-group rat pups were anesthetized with $2.5 \%$ halothane (balance: room air), and the right common carotid artery was surgically exposed and permanently ligated with 5-0 surgical silk. After surgery, the pups were returned to their dams for a 1 or $24 \mathrm{~h}$ recovery before hypoxia. On P7, the preconditioned and non-preconditioned groups were placed in airtight $500 \mathrm{ml}$ containers partially submerged in a $37^{\circ} \mathrm{C}$ water bath through which humidified $8 \%$ oxygen (balance: nitrogen) was maintained at a flow rate of $3 \mathrm{~L} / \mathrm{min}$ for
$2 \mathrm{~h}$. After the hypoxia had been completed, the rat pups were returned to their cage.

A gross neuropathological examination was performed on P30 to compare the differences in HI brain injury between the preconditioned $(n=50)$ and non-preconditioned $(n=60)$ rat pups. The severity of HI brain injury was categorized as follows: normal, mild atrophy, moderate atrophy, and severe damage (atrophy with cystic cavitation of the cerebral hemisphere ipsilateral to the artery ligation) (Vannucci et al., 1995).

Tissue sectioning after carotid-artery ligation. One or $24 \mathrm{~h}$ after carotidartery ligation, rat pups were anesthetized using 2.5\% halothane (balance: room air) and perfused with PBS, $\mathrm{pH} 7.4$, containing $4 \%$ paraformaldehyde. The brains were removed, postfixed in the same solution overnight at $4^{\circ} \mathrm{C}$, and then incubated at $4^{\circ} \mathrm{C}$ in $30 \%$ sucrose phosphate buffer for $48 \mathrm{~h}$. Brain sectioning (15 $\mu \mathrm{m}$ thick) for immunochemistry was done on frozen sections.

Immunohistochemistry. Brain sections were fixed with $4 \%$ paraformaldehyde in PBS for $1 \mathrm{~h}$ at room temperature and then washed twice with PBS. The sections were incubated with blocking solution containing primary antibodies at $4^{\circ} \mathrm{C}$ overnight and, on the next day, with secondary antibodies in blocking solution at room temperature for $1 \mathrm{~h}$. The primary antibodies used were anti-phosphorylated CREB (pCREB) (1:100; Upstate), anti-VEGF-A (1:200; Millipore Bioscience Research Reagents), anti-VEGFR-1 (1:50; Millipore Bioscience Research Reagents), and antiVEGFR-2 (1:100; Millipore Bioscience Research Reagents). Biotinylated goat anti-mouse, anti-goat, or anti-rabbit IgG were used (all 1:200). Biotin signals were detected using $0.5 \mathrm{mg} / \mathrm{ml} \mathrm{3} 3^{\prime} 3^{\prime}$-diaminobenzidine/ $0.003 \% \mathrm{H}_{2} \mathrm{O}_{2}$ as a substrate. Results were recorded using a microscope (Eclipse E400; Nikon).

Double-fluorescence immunocytochemistry. After blocking (1× PBS, $20 \%$ fetal bovine serum, $5 \%$ gelatin, and $0.1 \%$ Triton X-100) for $1 \mathrm{~h}$, the slides were incubated overnight at $4^{\circ} \mathrm{C}$ with a mixture of two of the following primary antibodies: anti-CD31 (1:100; Bioscience Research Reagents), anti-VEGF-A (1:100; Millipore Bioscience Research Reagents or Santa Cruz Biotechnology), anti-VEGFR-1 (1:50; Millipore Bioscience Research Reagents), anti-VEGFR-2 (1:100; Millipore Bioscience Research Reagents), anti-pCREB (1:100; Upstate), anti-neuronal nuclear antigen (NeuN) (1:200; Millipore Bioscience Research Reagents), or anti-glial fibrillary acidic protein (GFAP) (1:400; Millipore Bioscience Research Reagents). The slides were washed three times with 0.1 м PBS and then incubated with Texas Red-conjugated anti-rabbit or antimouse IgG and FITC-conjugated anti-mouse, anti-rabbit, or anti-goat IgG (1:200 in blocking reagents; Jackson ImmunoResearch) for $1 \mathrm{~h}$ at room temperature. The fluorescence signals were detected, and the results were recorded using a microscope (Eclipse E400; Nikon) at excitation/emission wavelengths of 596/615 nm (Texas Red, red) and 470/505 nm (FITC, green).

Measuring brain damage after hypoxic ischemia. To determine the effects of VEGF-A, VEGFR-1, or VEGFR-2 on the neuroprotection of $24 \mathrm{~h}$ ligation preconditioning, the $24 \mathrm{~h}$ ligation-preconditioned rat pups with different intracerebroventricular pretreatment protocols were killed after they had been anesthetized with $2.5 \%$ halothane on P14. The $1 \mathrm{~h}$ ligation-non-preconditioned pups with intracerebroventricular vehicle injection before hypoxia were used as another control group to compare with the $24 \mathrm{~h}$ ligation pups. After the brains had been perfused with saline, they were removed and then immersion fixed in $4 \%$ paraformaldehyde in $0.1 \mathrm{M}$ of PBS overnight at $4^{\circ} \mathrm{C}$. The next day, they were cryoprotected in $30 \%(\mathrm{w} / \mathrm{v})$ sucrose in $0.1 \mathrm{M}$ of PBS. The brains were serially sectioned ( $40 \mu \mathrm{m}$ thick) coronally from the genu of the corpus callosum to the end of the dorsal hippocampus and then stained with cresyl violet. The cross-sectional areas of the striatum, cortex, and hippocampus in the five reference planes corresponding approximately to plates 15, 18, 27, 31 , and 39 in a rat brain atlas (Paxinos and Watson, 1986) were assessed manually by tracing the histological area using a computerized image analysis system (Image-Pro Plus 4.5) linked to the E400 microscope. The total cross-sectional area in each brain region was then calculated in all sections assessed, and the percentage of area loss in the lesioned versus the non-lesioned hemisphere was determined for each rat pup.

Intracerebroventricular infusion of oligodeoxynucleotides. P6 rat pups were anesthetized using $2.5 \%$ halothane and then intracerebroventricu- 
larly infused with antisense or scrambled oligodeoxynucleotides (ODNs) in the right cerebral hemisphere at designated time points using a 30 gauge needle on a $10 \mu \mathrm{l}$ Hamilton syringe (Lee et al., 2004). The location of each injection in relation to the bregma was $2.0 \mathrm{~mm}$ posterior to, $1.5 \mathrm{~mm}$ lateral to, and $2.0 \mathrm{~mm}$ beneath the skull surface. ODNs were freshly reconstituted in vehicles that were filtered through $0.22 \mathrm{~mm}$ membranous filters before use, and the infusion rate was $1 \mu \mathrm{l} / \mathrm{min}$ using a Hamilton syringe pump. The schedules of antisense ODN injection for VEGF-A, VEGFR-1, and VEGFR-2 were made according to their respective inhibition effect on VEGF-A, VEGFR-1, or VEGFR-2 expression $24 \mathrm{~h}$ after ligation preconditioning by Western blots.

VEGF-A antisense oligodeoxynucleotide infusion. Antisense ODNs were used to determine the potential involvement of VEGF-A in the neuroprotective effect of preconditioning induced by $24 \mathrm{~h}$ carotid-artery ligation. The sequences for phosphorothioate ODNs (Blossom-bio Ltd) were prepared as described previously (Yang et al., 2002). The first intracerebroventricular ODN infusion was given $1 \mathrm{~h}$ before carotid-artery ligation, and the second infusion was given $11 \mathrm{~h}$ after ligation. The ODNs were infused in a $2 \mu \mathrm{l}(9 \mathrm{nmol})$ bolus per intracerebroventricular injection, for a total volume of $4 \mu \mathrm{l}(18 \mathrm{nmol})$ after two injections per rat. Random ODN in which the proportion of each nucleotide was identical to that of antisense ODN was the control. Sequences for the ODNs, based on the rat GLAST (EAAT1), were as follows: 5' -TGGCTTGAAGATGTACTCGAT-3' (VEGF-A antisense ODN); and 5'-TACGTAGTATGGTGTACGATC-3' (VEGF-A scrambled ODN).

Twenty-four hours after ligation, all groups underwent $8 \%$ oxygen hypoxia for $2 \mathrm{~h}$. The degree of brain damage was measured using brain area reduction on P14. To determine the effect of VEGF-A antisense ODN, the cerebral cortices were collected for protein expression 7 and $13 \mathrm{~h}$ after the last ODN or vehicle infusion.

VEGFR-1 and VEGFR-2 antisense oligodeoxynucleotide infusions. To determine the potential role of VEGFR-1 or VEGFR-2 in the neuroprotective effect of preconditioning induced by $24 \mathrm{~h}$ artery ligation, antisense ODNs were used. A set of modified 20-mer antisense-ODNs targeted to the VEGFR-1 or VEGFR-2 gene was synthesized commercially (Blossom-Bio), as described previously (Rosenstein et al., 2003). To avoid antisense-ODN degradation, all ODNs were end capped with a phosphorothioate modification at their $3^{\prime}$-terminal positions. The ODN sequences were as follows: 5'-GTCGCTCTTGGTGCTATA-3' (VEGFR-1 antisense), 5' -CCTCCACTCTTTTCTCAG-3' (VEGFR-2 antisense), and 5'-TGCTGGCATGTGCGTTGT-3' (missense control).

The ODNs were reconstituted in $0.1 \%$ BSA/PBS, pH 7.4, at a concentration of $3.75 \mathrm{nmol} / \mu \mathrm{l}$. The first VEGFR-1 ODN was infused $1 \mathrm{~h}$ before carotid-artery ligation, and the second was infused $5 \mathrm{~h}$ after ligation. The first VEGFR-2 ODN was infused $1 \mathrm{~h}$ before ligation, and the second one was infused $11 \mathrm{~h}$ after ligation. The VEGFR-1 or VEGFR-2 ODNs were infused in a $2 \mu \mathrm{l}(7.5 \mathrm{nmol})$ bolus per intracerebroventricular injection, for a total volume of $4 \mu \mathrm{l}(15 \mathrm{nmol})$ after two injections per rat. Control rats received $2 \mu \mathrm{l}$ of filtered $0.1 \%$ BSA/PBS. Twenty-four hours after ligation, all groups underwent $8 \%$ oxygen hypoxia for $2 \mathrm{~h}$. The degree of brain damage was measured on P14. To determine the effect of antisense ODN, the cerebral cortices were collected 7 and $19 \mathrm{~h}$ after the last infu-
1 h-ligation
24 h-ligation



$18 / 60(30 \%)$

$15 / 60(25 \%)$

1 h-ligation

$21 / 60(35 \%)$



24 h-ligation
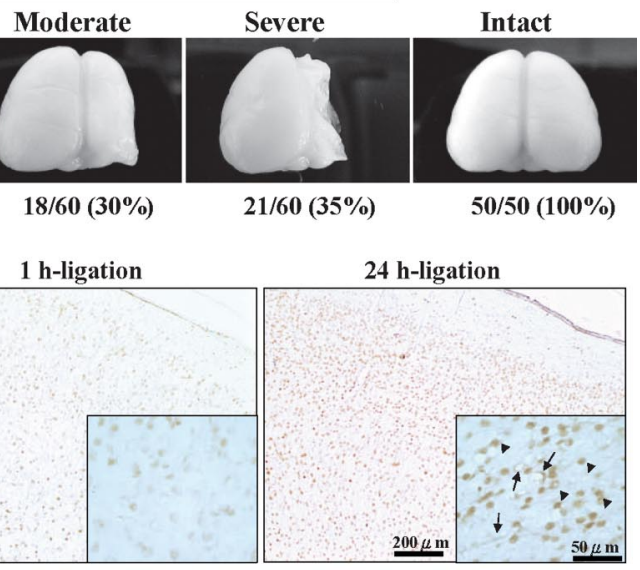

$0 \mu \mathrm{m}$

Figure 1. A, Preconditioning established by delaying the onset of hypoxia for $24 \mathrm{~h}$ after unilateral carotid-artery ligation in rat pups provided complete neuroprotection. A gross neuropathological examination on P30 rats after hypoxic ischemia on P7 showed $100 \%$ (50 of 50) of the $24 \mathrm{~h}$ ligation (preconditioned) group had complete neuroprotection; in contrast, $90 \%$ of the $1 \mathrm{~h}$ ligation. The increased pCREB expression in the $24 \mathrm{~h}$ ligation group was located primarily in neurons (arrowheads) and vessels (arrows, insets). C, Representative double-immunofluorescence staining in the preconditioned group showed that the pCREB ${ }^{+}$ cells were mainly vascular endothelial cells (coexpressed CD31, arrows) or neurons (coexpressed NeuN, arrowheads).

sion for VEGFR-1 ODN and 7 and $13 \mathrm{~h}$ after the last injection for VEGFR-2 ODN.

Cell culture. Rat immortalized hippocampal neuronal cells (H19-7) and mouse immortalized cerebral endothelial (b.End3) cells were purchased from American Type Culture Collection. The cells were plated at a density of $4 \times 10^{5}$ cells per dish and grown for $24 \mathrm{~h}$ in a normoxia plus $5 \% \mathrm{CO}_{2}$ atmosphere under DMEM (Invitrogen) with $10 \%$ fetal bovine serum (FBS) and $100 \mathrm{U} / \mathrm{ml}$ penicillin-streptomycin (Invitrogen) (complete medium) at $37^{\circ} \mathrm{C}$ for b.End 3 cells or under the complete medium plus $200 \mu \mathrm{g} / \mathrm{ml} \mathrm{G} 418$ selection at $33^{\circ} \mathrm{C}$ for $\mathrm{H} 19-7$ cells. To initiate neuron differentiation, the H19-7 cells were maintained in complete medium plus N2 supplements and treated with $10 \mathrm{ng} / \mathrm{ml}$ basic fibroblast growth factor (Sigma) under $5 \% \mathrm{CO}_{2}$ at $39^{\circ} \mathrm{C}$ for $2 \mathrm{~d}$ (Sung et al., 2001). The culture mediums were replenished every $48 \mathrm{~h}$.

Oxygen-glucose deprivation preconditioning on neuronal cells and endothelial cells. For the induction of oxygen-glucose deprivation (OGD), the H19-7 and b.End3 cells were washed twice with glucose-free DMEM medium (OGD medium) and switched to OGD medium with 10\% FBS and placed in a hypoxia chamber (NexBiOxy Taiwan) within a humidified modular incubator (Forma). The chambers were flushed with a gas mixture of $95 \% \mathrm{~N}_{2} / 5 \% \mathrm{CO}_{2}$ at $3 \mathrm{~L} / \mathrm{min}$ for $30 \mathrm{~min}$ at $39^{\circ} \mathrm{C}$ for $\mathrm{H} 19-7$ cells or at $37^{\circ} \mathrm{C}$ for b.End 3 cells. After flushing, the chambers were sealed and maintained under a gas mixture of $95 \% \mathrm{~N}_{2} / 5 \% \mathrm{CO}_{2}$, and OGD was performed for 2, 4, 8, 16, or $24 \mathrm{~h}$ for the H19-7 cells or 3, 6, 12, 18, or $24 \mathrm{~h}$ for the b.End 3 cells. OGD was terminated by returning the cell culture to a normoxic condition and replacing of the medium with complete me- 
A
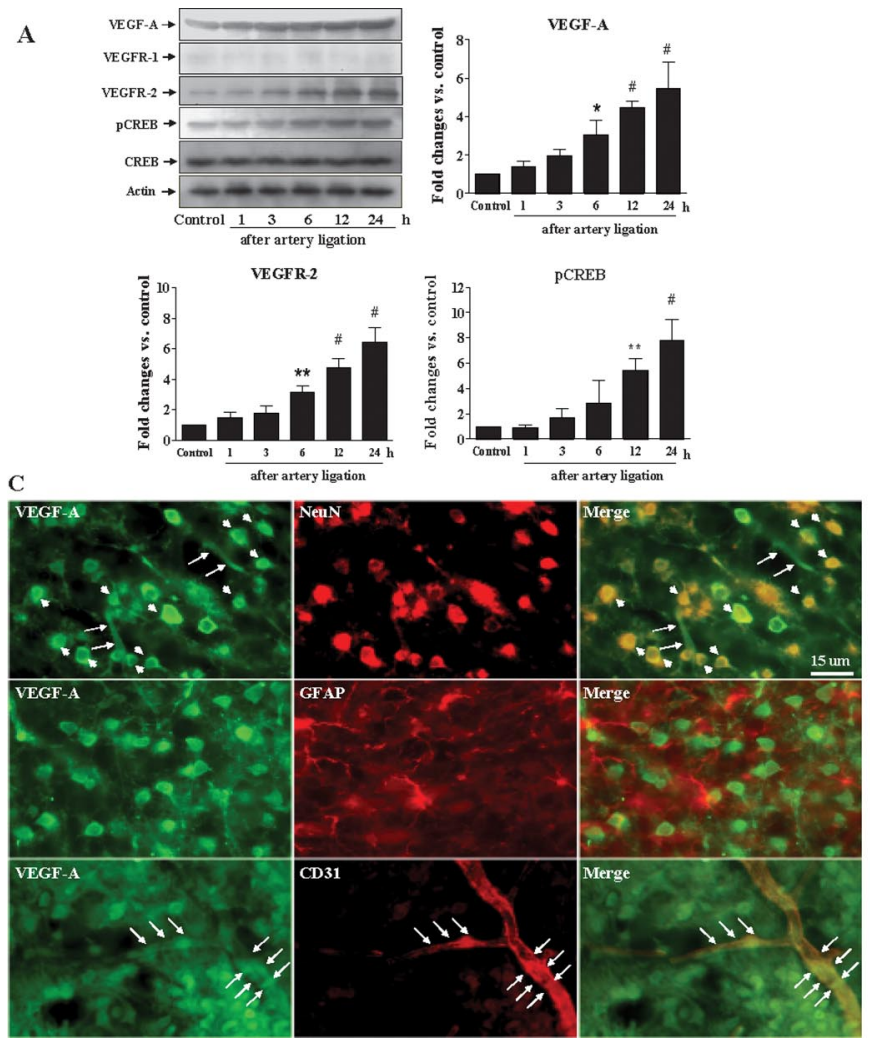

VEGF-A
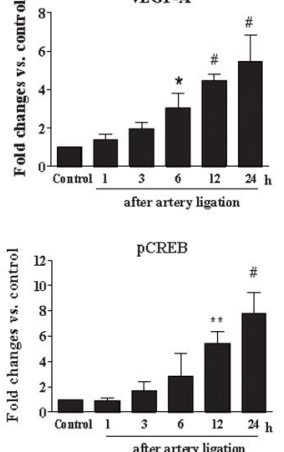

B

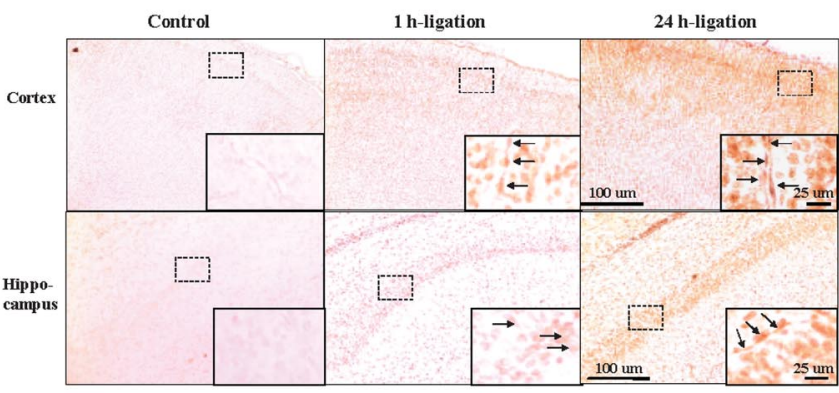

D

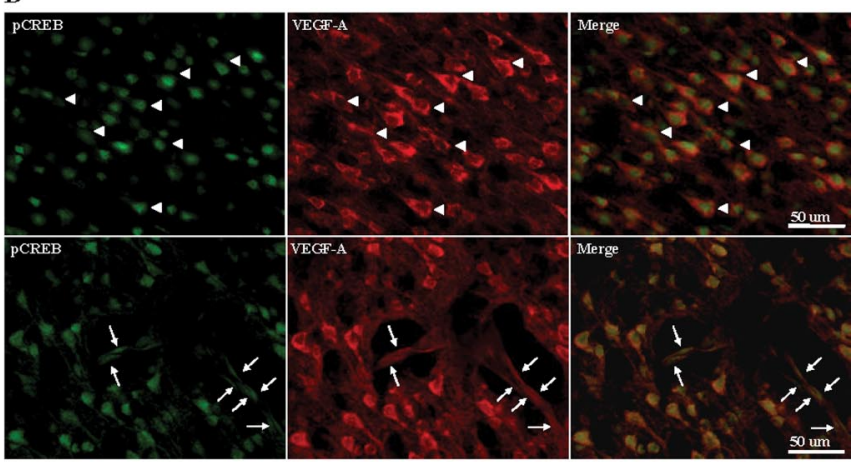

Figure 2. Preconditioning induced by $24 \mathrm{~h}$ carotid-artery ligation increased VEGF-A and $\mathrm{pCREB}$ expression in the neurons and vascular endothelial cells of the ipsilateral cerebral cortex of $\mathrm{P7}$ rat pups. $A$, VEGF-A increased time dependently between 6 and $24 \mathrm{~h}$ after ligation, and the $p$ CREB levels also increased 12 and $24 \mathrm{~h}$ after ligation. ${ }^{*} p<0.05$, ${ }^{* *} p<0.01,{ }^{\#} p<0.001$ compared with the nonligation control group. Values are means \pm SD from four independent experiments. $\boldsymbol{B}$, Immunohistochemistry showed that, compared with the control group, VEGF-A expression in the ipsilateral cortex and hippocampus was slightly higher in the $1 \mathrm{~h}$ ligation (non-preconditioned) group but markedly higher in the $24 \mathrm{~h}$ ligation (preconditioned) group. The increased VEGF-A expression in the preconditioned group was primarily in neurons and vessels (arrows, insets). Representative immunofluorescence staining in the preconditioned group confirmed that most of the VEGF-A ${ }^{+}$cells were neurons (arrowheads) that coexpressed NeuN or vascular endothelial cells (arrows) that coexpressed (D31, instead of astroglial cells that coexpressed GFAP ( $\boldsymbol{C}$ ) and that most of the VEGF- $A^{+}$neurons (arrowheads) and endothelial cells (arrows) also coexpressed pCREB (D).

dium plus $\mathrm{N} 2$ supplements at $39^{\circ} \mathrm{C}$ for the $\mathrm{H} 19-7$ cells or with complete medium at $37^{\circ} \mathrm{C}$ for the b.End 3 cells.

For OGD preconditioning experiments (Hillion et al., 2006; Chang et al., 2008), the H19-7 and b.End3 cells were grown for $24 \mathrm{~h}$ in complete medium. The cells were then washed twice with OGD medium, switched to OGD medium, and then subjected to OGD under $95 \% \mathrm{~N}_{2} / 5 \% \mathrm{CO}_{2}$ for $5 \mathrm{~h}$ at $37^{\circ} \mathrm{C}$ for the b.End 3 cells and at $39^{\circ} \mathrm{C}$ for the $\mathrm{H} 19-7$ cells. The cells not subjected to OGD preconditioning (control) were maintained under the normoxic condition in complete medium at $37^{\circ} \mathrm{C}$ for the b.End 3 cells and plus $200 \mu \mathrm{g} / \mathrm{ml} \mathrm{G} 418$ selection at $39^{\circ} \mathrm{C}$ for the H19-7 cells. After $5 \mathrm{~h}$ of OGD, the control and OGD-preconditioned cells were maintained in complete medium under normoxia for $24 \mathrm{~h}$ for developing cellular tolerance and then again exposed to OGD in the hypoxic chamber for $24 \mathrm{~h}$.

To evaluate the role of VEGF-A and VEGFR-2 in the protective effect of OGD preconditioning in the neuronal cells and endothelial cells, the cells were pretreated with a human neutralizing antibody against VEGF-A ( 5 or $10 \mu \mathrm{g} / \mathrm{ml}$; R \& D Systems) or control IgG (5 or $10 \mu \mathrm{g} / \mathrm{ml}$; R \& D Systems), or SU5416, a specific inhibitor of VEGFR-2 (5 or $10 \mu \mathrm{M}$; Sigma) or its vehicle $5 \mathrm{~min}$ before the $5 \mathrm{~h}$ OGD preconditioning (Wick et al., 2002). After the cells had been washed twice and placed in glucosefree OGD medium, the VEGF-A neutralizing antibody or IgG, or SU5416 or its vehicle was added to the H19-7 and b.End3 cells before OGD preconditioning. After preconditioning, the cells were then maintained in complete medium under normoxia for $24 \mathrm{~h}$ before being exposed to $24 \mathrm{~h}$ OGD. Cell viability was measured $24 \mathrm{~h}$ after OGD.

Transient transfection. A SacI/BamHI-digested fragment containing CREB133 mutant cDNA from pCMV-CREB133 was inserted into the SacI/BamHI site of pIRES2-ZsGreen1 (Clontech), which was then designated as MCREB133-ZsGreen1. The plasmids were prepared by using QIAfilter Plasmid Midi kits (Qiagen). The MCREB133 expressed a mu- tant variant of the human CREB protein that contains a serine to alanine mutation corresponding to amino acid 133 in the mouse CREB protein. This mutation blocks CREB activation, thus preventing transcription. The plasmid pIRES2-ZsGreen1 (Clontech), which contained green fluorescent protein, was used as an internal control to determine the transfected efficiency with fluorescence microscopy. Each vector was transfected to the differentiated H19-7 and b.End3 cells using EXGen 500 in vitro transfection (Fermantas), following the instructions of the manufacturer, $36 \mathrm{~h}$ before OGD preconditioning.

Cell viability. Twenty-four hours after OGD, cell viability was quantitatively assessed using a cell proliferation kit (XTT: sodium $3^{\prime}$-[1(phenylaminocarbonyl)-3, 4-tetrazolium]-bis (4-methoxy-6-nitro) benzene sulfonic acid hydrate) (Roche) for the production of orange formazan dye, an index of the number of viable cells in culture. H19-7 cells $\left(1.0 \times 10^{6}\right)$ and b.End 3 cells $\left(1.0 \times 10^{6}\right)$ were incubated with XTT labeling reagent for $6 \mathrm{~h}$ at 39 and $37^{\circ} \mathrm{C}$, respectively. The optical density at $492 \mathrm{~nm}$ was monitored, and cell viability was expressed as the percentage of optical density in the treated group over that of the vehicle-treated control.

Western blot analysis. Brain tissue or cells were homogenized in cold lysis buffer as described previously (Lee et al., 2004). Samples (50-180 $\mu \mathrm{g}$ ) were resolved using $10 \%$ SDS-PAGE and blotted electrophoretically to polyvinylidene fluoride membranes. The membranes were incubated with primary antibodies, and immunoreactivity was detected using horseradish-conjugated secondary antibody and then visualized using enhanced chemiluminescence. The following primary antibodies were used: anti-VEGF-A (1:2000; Oncogene), anti-VEGFR-1 (1:400; Santa Cruz Biotechnology), anti-VEGFR-2 (1:1000; Millipore Bioscience Research Reagents), anti-pCREB (1: 1000; Upstate), anti-CREB (1:2000; 
A

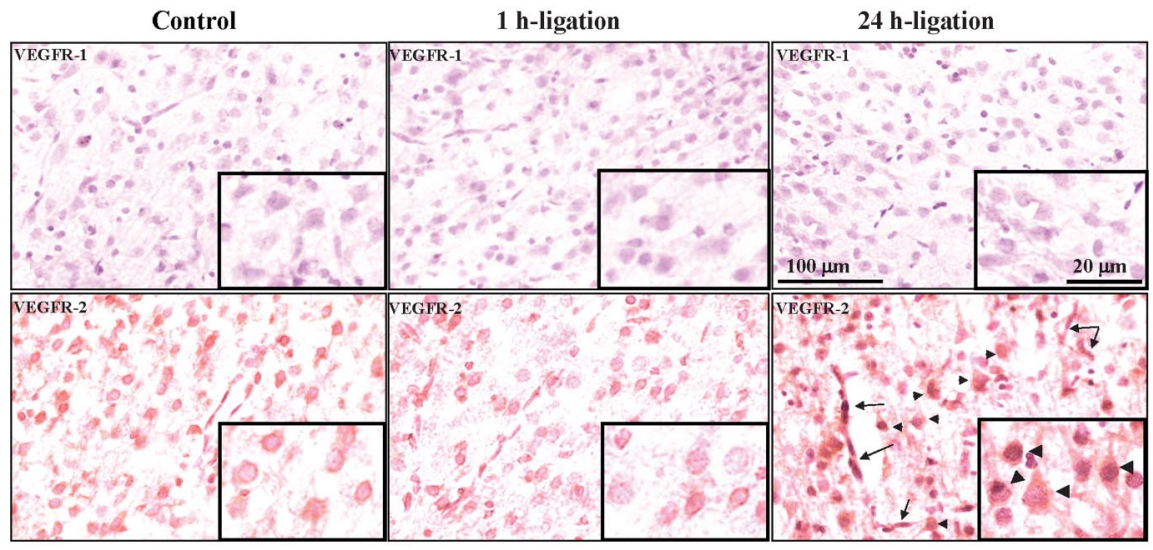

\section{B}



C

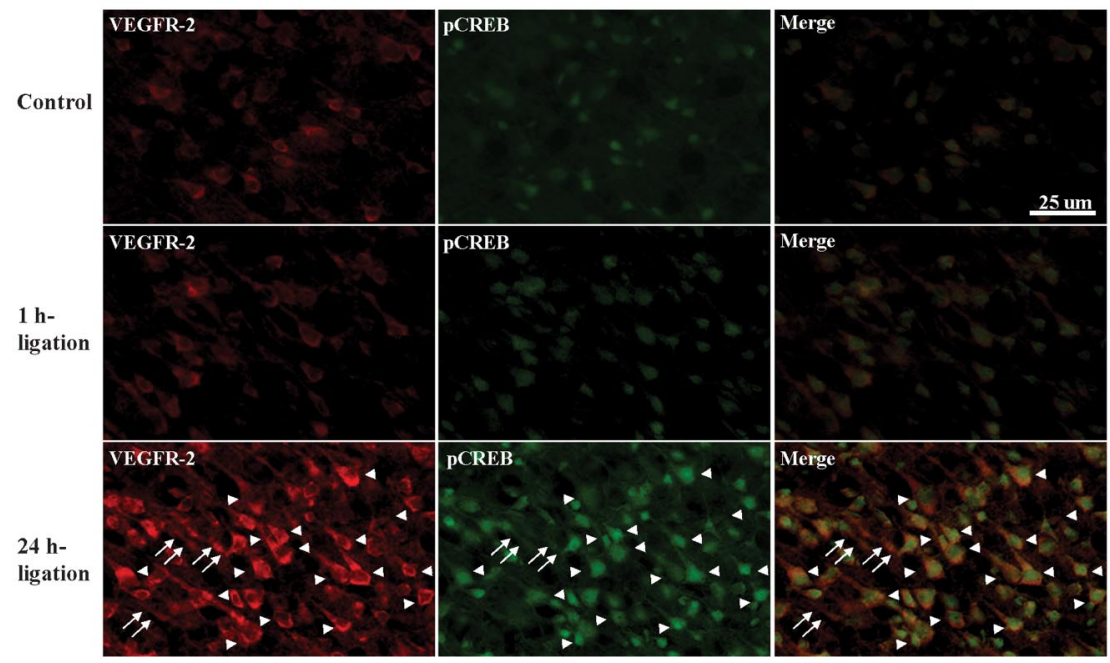

Figure 3. Preconditioning induced by $24 \mathrm{~h}$ carotid-artery ligation increased VEGFR-2 and $p$ CREB expression in neurons and vessels of the ipsilateral cerebral cortex. $\boldsymbol{A}$, Immunohistochemistry showed that the $24 \mathrm{~h}$ ligation (preconditioned) group had higher VEGFR-2, but not VEGFR-1, expression in neurons (arrowheads, insets) and vessels (arrows) compared with the $1 \mathrm{~h}$ ligation (non-preconditioned) group and the nonligation control group (counterstained with hematoxylin). B, Immunofluorescence
Upstate), and anti-actin (1:5000; Millipore Bioscience Research Reagents).

Statistics. Statistical significance, set at $p<$ 0.05 , was determined using nonparametric one-way ANOVA. Values are means \pm SD unless otherwise indicated.

\section{Results}

\section{In vivo studies}

Ligation preconditioning increased $p C R E B$ expression in vascular endothelial cells and neurons

A gross neuropathological examination was done on P30 to compare the differences in HI brain damage between the $24 \mathrm{~h}$ preconditioned rat pups and the $1 \mathrm{~h}$ nonpreconditioned pups. One hundred percent of the preconditioned-group rats had complete neuroprotection, whereas $90 \%$ of the non-preconditioned-group rats had variable degrees of damage: $10 \%$ normal, $25 \%$ mild atrophy, $30 \%$ moderate atrophy, and 35\% severe atrophy with cystic cavitation (Fig. 1A). Immunohistochemistry showed that, compared with the P7 nonligation control rat pups, pCREB expression in the ipsilateral cerebral cortex did not change $1 \mathrm{~h}$ after ligation in the non-preconditioned group but was markedly increased $24 \mathrm{~h}$ after ligation in the preconditioned group (Fig. $1 B)$. Double-immunofluorescence analysis in the preconditioned group showed that pCREB expression was located mainly in the vascular endothelial cells or neurons because most of the pCREB-positive ( pCREB $^{+}$) cells coexpressed CD31 or NeuN (Fig. 1C).

Ligation preconditioning increased VEGF$A$ and $p C R E B$ expression in vascular endothelial cells and neurons

To determine whether VEGF-A is the upstream transducer leading to CREB activation in vascular endothelial cells and neurons, we first used Western blots to examine VEGF-A and pCREB expression after preconditioning. We found that VEGF-A levels increased time dependently in the ipsilateral cortex: the increase began $6 \mathrm{~h}$ after ligation $(p<0.05)$ and continued until at least $24 \mathrm{~h}$ after ligation $(p<0.001)$ (Fig. 2A). The pCREB levels also increased in the ipsilateral cortex $12 \mathrm{~h}$ after ligation $(p<0.01)$ and reached a peak level $24 \mathrm{~h}$ after ligation $(p<0.001)$. Immunohisto-

\footnotetext{
analysis showed most of the VEGFR-2 ${ }^{+}$nonvascular cells (arrowheads) of the preconditioned group coexpressed NeuN but not GFAP. These VEGFR-2 ${ }^{+}$cells also coexpressed VEGF-A. C, The $24 \mathrm{~h}$ preconditioned group had higher expression of VEGFR-2 and $p$ CREB in vessels and neurons compared with the control or $1 \mathrm{~h}$ non-preconditioned group. The neurons (arrowheads) and vessels (arrows) with higher VEGFR-2 expression in the preconditioned group also coexpressed pCREB.
} 
A


B



Cortex

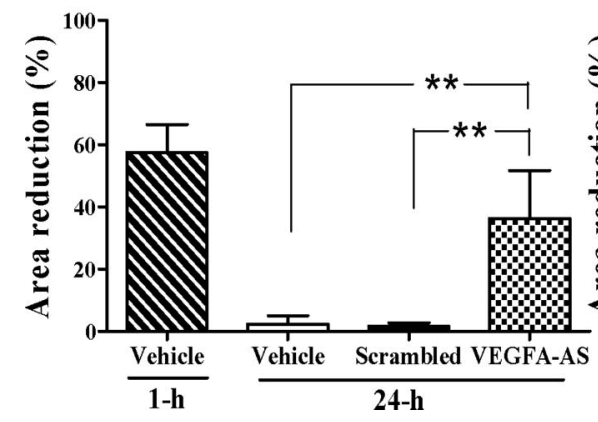

Hippocampus

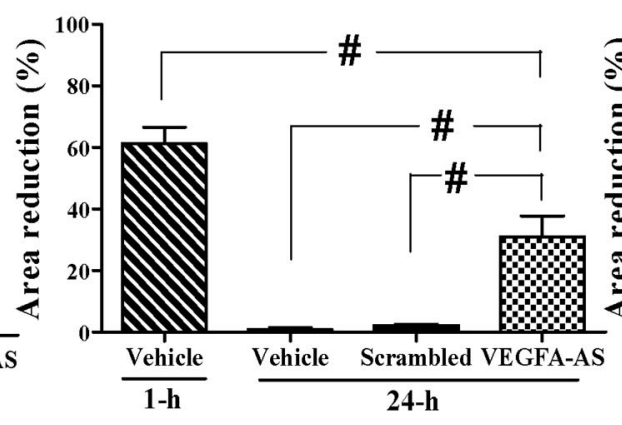

Striatum

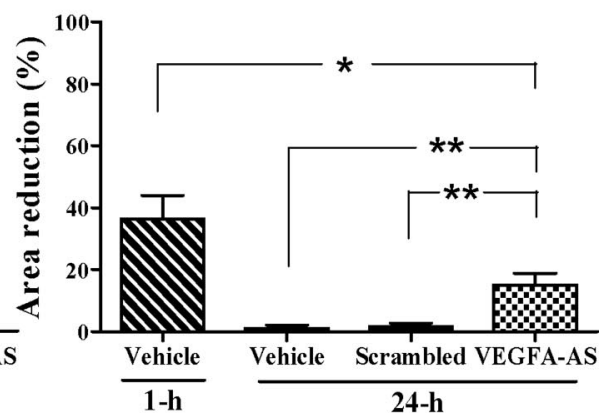


chemistry further confirmed that, compared with the controls, VEGF-A expression in the ipsilateral cortex and hippocampus had only mildly increased $1 \mathrm{~h}$ after ligation but was markedly upregulated $24 \mathrm{~h}$ after ligation (Fig. 2 B). The increased VEGF-A expression in the preconditioned group was primarily in the vessels and neurons. Additional double-immunofluorescence analysis in the preconditioned group confirmed that VEGF-A was expressed mainly in the vascular endothelial cells and neurons instead of astrocytes because most of the VEGF-A ${ }^{+}$cells coexpressed CD31 or NeuN but not GFAP (Fig. 2C). In addition, most of the VEGF-A ${ }^{+}$neurons and endothelial cells also coexpressed pCREB (Fig. 2D). These findings suggested that preconditioning induced by $24 \mathrm{~h}$ artery ligation increased VEGF-A and pCREB expression in both the neurons and vascular endothelial cells of the ipsilateral cortex.

\section{Ligation preconditioning increased VEGFR-2 and $p C R E B$ expression in vessels and neurons}

Using Western blotting, we found that VEGFR-2, but not VEGFR-1, levels in the ipsilateral cortex increased time dependently between 6 and $24 \mathrm{~h}$ after ligation (Fig. 2A). Immunohistochemistry showed very few VEGFR- $1^{+}$cells in the cortices of P7 control-group pups; in contrast, it showed many VEGFR-2 ${ }^{+}$ cells. VEGFR-2, but not VEGFR-1, expression in vessels and neuron-like cells increased in the ipsilateral cortices of the preconditioned group compared with that of the control and nonpreconditioned groups (Fig. 3A). Immunofluorescence analysis confirmed that most of the VEGFR-2 ${ }^{+}$nonvascular cells in the cortices of the preconditioned group were neurons instead of astroglial cells and that these VEGFR- $2^{+}$neurons also coexpressed VEGF-A (Fig. 3B), which suggested that VEGFR-2 may support the autocrine survival function of VEGF-A after preconditioning. In addition, the neurons and vessels with increased VEGFR-2 expression in the preconditioned group also coexpressed pCREB (Fig. 3C). These findings suggested that preconditioning induced by $24 \mathrm{~h}$ artery ligation also increased VEGFR-2 and pCREB expression in neurons and vessels in the ipsilateral cortex.

\section{VEGF-A was required for CREB phosphorylation and protection induced by $24 \mathrm{~h}$ ligation preconditioning}

To investigate whether VEGF-A is required for CREB phosphorylation and the protective effects of $24 \mathrm{~h}$ ligation preconditioning, we injected each P6 preconditioned-group rat pup intracerebroventricularly with VEGF-A antisense (AS) ODN (VEGF-A AS) in the right cerebral hemisphere before and after ligation. Compared with vehicle or scrambled ODN, VEGF-A AS significantly reduced the levels of VEGF-A, VEGFR-2, and pCREB, but it did not affect VEGFR-1 or total CREB in the ipsilateral cortex after preconditioning (Fig. 4A). Compared with vehicle or scrambled ODN infusion, VEGF-A AS treatment significantly

\section{$\leftarrow$}

Figure 4. VEGF-A was required for CREB phosphorylation and protection induced by $24 \mathrm{~h}$ carotid-artery ligation preconditioning. $A$, Compared with vehicle or scrambled ODN, intracerebroventricular infusions of VEGF-A antisense ODN (VEGF-A AS) markedly reduced VEGF-A, VEGFR-2, and pCREB expression, but it did not affect VEGFR-1 levels of the preconditioned rat pups. ${ }^{\#} p<0.001$ compared with the vehicle-treated or scrambled ODN-treated group. Values are means \pm SD from four independent experiments. $\boldsymbol{B}$, VEGF-A AS treatment significantly reduced the protective effect of $24 \mathrm{~h}$ ligation preconditioning in the cortex, hippocampus, and striatum compared with vehicle or scrambled ODN infusion $\left({ }^{* *} p<0.01,{ }^{\#} p<0.001\right)$. The $24 \mathrm{~h}$ preconditioned group treated with VEGF-A AS had significantly less area loss in the hippocampus $\left({ }^{\sharp} p<0.001\right)$ and striatum $\left({ }^{*} p<0.05\right)$ than did the $1 \mathrm{~h}$ non-preconditioned group. $n=$ $9-10$ rats per group. Values are means \pm SD. reduced the protective effect in the cortex (both $p<0.01$ ), hippocampus (both $p<0.001$ ), and striatum (both $p<0.01$ ) of the preconditioned group (Fig. $4 \mathrm{~B}$ ), which suggested that VEGF-A is required for CREB activation and the protective effect induced by $24 \mathrm{~h}$ ligation preconditioning. The $24 \mathrm{~h}$ preconditioned group treated with VEGF-A AS still had significantly less area loss, especially in the hippocampus $(p<0.001)$ and striatum $(p<$ $0.05)$, than did the $1 \mathrm{~h}$ non-preconditioned group treated with vehicle.

VEGFR-2, not VEGFR-1, was required for CREB phosphorylation and protection induced by $24 \mathrm{~h}$ ligation preconditioning

We next used AS ODN specific for VEGFR-1 (VEGFR-1 AS) or VEGFR-2 (VEGFR-2 AS) to inhibit their respective expression to examine their roles in CREB phosphorylation and the protection afforded by $24 \mathrm{~h}$ ligation preconditioning. Rat pups were intracerebroventricularly infused with VEGFR-1 AS, VEGFR-2 AS, missense scrambled ODNs, or vehicle in the right cerebral hemisphere before and after ligation. VEGFR-1 AS significantly reduced the expression of VEGFR-1 $(p<0.05)$ but did not alter the increased expression of VEGFR-2 or pCREB after $24 \mathrm{~h}$ ligation preconditioning (Fig. 5A). In contrast, VEGFR-2 AS markedly reduced the expression of VEGFR-2 and pCREB (all $p<0.001$ ), but not of VEGFR-1, in the preconditioned group (Fig. $5 B$ ). In the preconditioned group, rat pups given VEGFR-2 AS showed significantly reduced protective effects in the cortex (all $p<$ 0.001 ), hippocampus (all $p<0.001$ ), and striatum (all $p<0.01$ ) compared with the rats given vehicle or scrambled ODN (Fig. $5 C)$. In contrast, VEGFR-1 AS did not reduce the protective effect of $24 \mathrm{~h}$ ligation preconditioning, which suggested that VEGFR-2 but not VEGFR-1 is required for CREB activation and the protective effect induced by $24 \mathrm{~h}$ artery ligation preconditioning. Compared with the $1 \mathrm{~h}$ non-preconditioned group treated with vehicle, the $24 \mathrm{~h}$ preconditioned group treated with VEGFR-2 AS still had significantly less area loss in the cortex $(p<0.001)$, hippocampus $(p<0.001)$, and striatum $(p<0.05)$.

\section{In vitro studies}

OGD preconditioning upregulated VEGF-A, VEGFR-2, and pCREB and protected against OGD cell death in neuronal cells and endothelial cells

To examine whether the VEGF-A/VEGFR-2 signaling that leads to CREB activation is critical for the protective effect of OGD preconditioning in neuronal cells and vascular endothelial cells, in vitro models of OGD preconditioning were established in immortalized H19-7 neuronal cells and b.End3 cerebral vascular endothelial cells. Cell viability, measured using an XTT assay, decreased progressively in the H19-7 cells and b.End3 cells as the duration of OGD increased up to $24 \mathrm{~h}$ : $~ 50 \%$ of the H19-7 cells and $\sim 60 \%$ of the b.End 3 cells survived compared with their respective non-OGD controls (Fig. 6A). OGD preconditioning for $5 \mathrm{~h}$ before $24 \mathrm{~h}$ OGD significantly increased the cell viability from 45 to $75 \%$ in the H19-7 cells and from 58 to $80 \%$ in the b.End 3 cells (both $p<0.001$ ) (Fig. 6B).

Western blots showed that $5 \mathrm{~h}$ of OGD preconditioning significantly upregulated the VEGF-A, VEGFR-2, and pCREB expression levels in the H19-7 cells and b.End3 cells (Fig. 7). VEGF-A levels were significantly increased at $1 \mathrm{~h}$ and continued for $24 \mathrm{~h}$ after OGD preconditioning in the H19-7 cells and b.End 3 cells (both $p<0.001$ ), respectively. The VEGFR-2 levels increased at $1 \mathrm{~h}$ after preconditioning in both H19-7 cells and b.End 3 cells, and the increased level was sustained for at least $24 \mathrm{~h}$ in H19-7 cells and for $12 \mathrm{~h}$ in b.End 3 cells after preconditioning. 
A


B
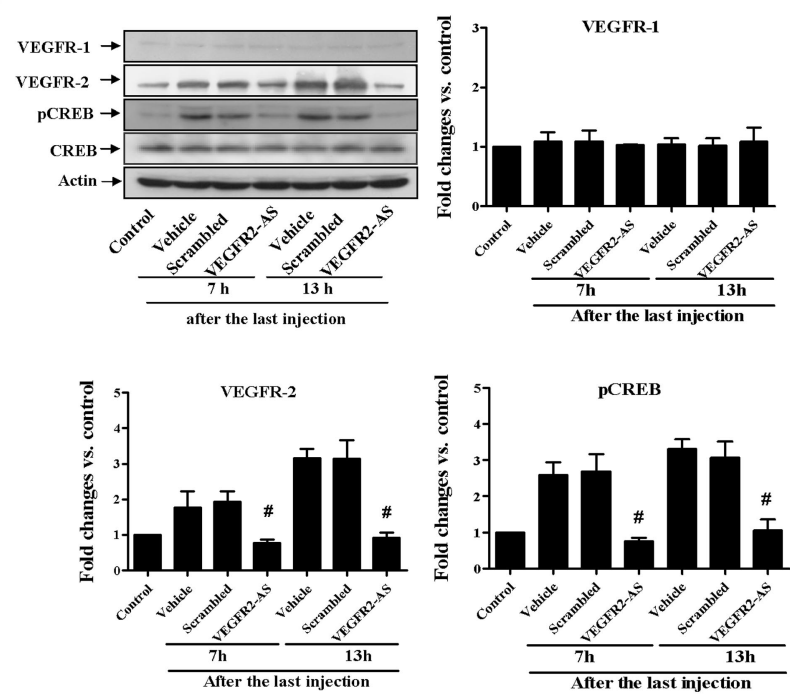

C
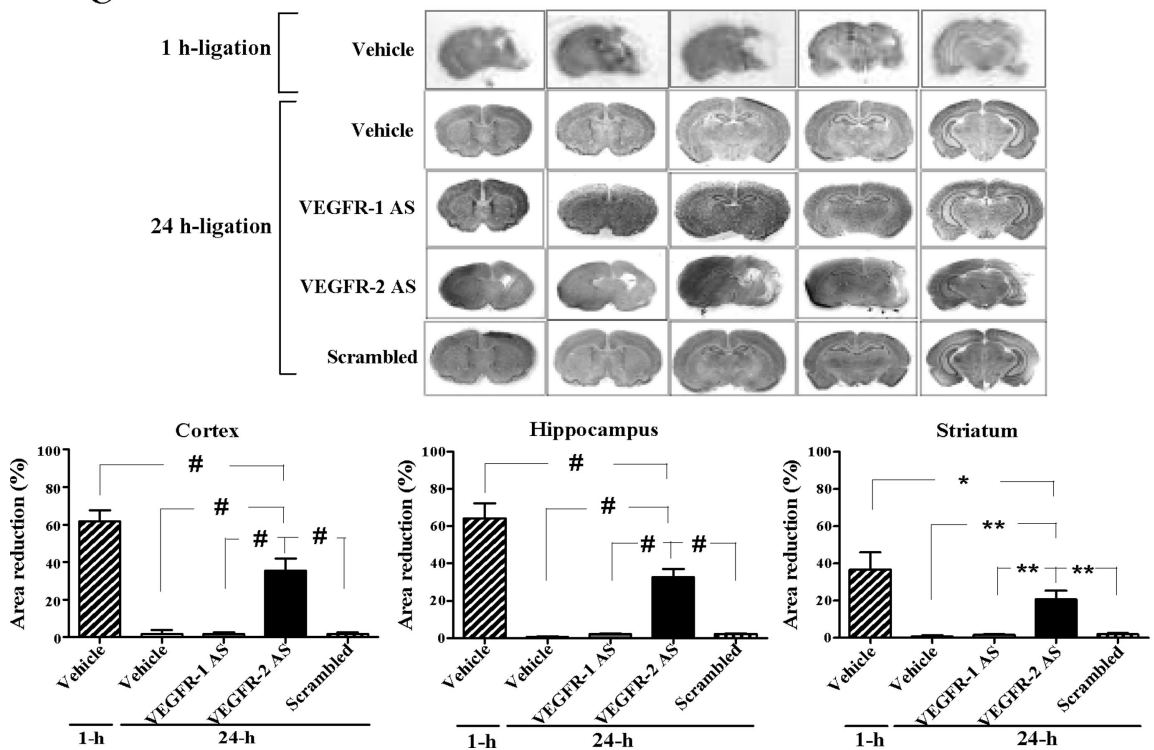

Figure 5. VEGFR-2, but not VEGFR-1, was required for CREB phosphorylation and the protective effects of $24 \mathrm{~h}$ carotid-artery ligation preconditioning. $\boldsymbol{A}$, Compared with vehicle or scrambled ODN, VEGFR-1 AS significantly reduced VEGFR-1 expression, but it did not alter VEGFR-2 or pCREB expression in the $24 \mathrm{~h}$ preconditioned group. $\boldsymbol{B}$, In contrast, VEGFR-2 AS markedly reduced
The pCREB levels increased $1 \mathrm{~h}$ after preconditioning in H19-7 cells and $3 \mathrm{~h}$ after preconditioning in b.End 3 cells; the increased pCREB levels in H19-7 cells and b.End 3 cells persisted for at least $24 \mathrm{~h}$ after preconditioning. These findings indicated that OGD preconditioning upregulated VEGF-A and VEGFR-2 expression and phosphorylated CREB in H19-7 cells and b.End3 cells; they also suggested that VEGF-A/VEGFR-2/CREB activation may underlie the protective effect of OGD preconditioning in neuronal cells and cerebral vascular endothelial cells.

VEGF-A/VEGFR-2 signaling was required for CREB activation and the protective effect of OGD preconditioning in neuronal cells and endothelial cells

To determine the role of VEGF-A and VEGFR-2 in the protective effect of OGD preconditioning against OGD cell death in neuronal cells and endothelial cells, we treated the H19-7 cells and b.End 3 cells with a neutralizing antibody against VEGF-A (VEGF-A Ab) or a VEGFR-2 inhibitor (SU5416) before OGD preconditioning. We found that, compared with control IgG, pretreatment with VEGF-A $\mathrm{Ab}$ in a concentration range of 5 or 10 $\mu \mathrm{g} / \mathrm{ml}$ significantly reduced the protective effect of OGD preconditioning in H19-7 cells (percentage of survival decreased from 75 to $40-45 \%$ ) and in b.End3 cells (decreased from 78 to $45-50 \%$ ) (Fig. $8 A$ ). Similarly, pretreating the cells with SU5416 (5 or $10 \mu \mathrm{M})$ significantly reduced the protective effect of OGD preconditioning in H19-7 cells (percentage of survival reduced from 75 to $40-45 \%$ ) and b.End3 cells (reduced from 78 to $45 \%$ ) compared with pretreating with vehicle (20\% DMSO/80\% PBS). Pretreatment of VEGF-A Ab $(10 \mu \mathrm{g} / \mathrm{ml})$ or SU5416 $(5 \mu \mathrm{M})$ before OGD preconditioning significantly reduced the increase in pCREB levels after OGD preconditioning in H19-7 cells and b.End 3 cells (Fig. $8 \mathrm{~B}$ ). These findings sug-

$\leftarrow$

VEGFR-2 and pCREB, but not VEGFR-1, expression in the preconditioned group. ${ }^{*} p<0.05,{ }^{\#} p<0.001$ compared with the vehicle-treated or scrambled ODN-treated group. Values are means \pm SD from four independent experiments. $C$, In the $24 \mathrm{~h}$ preconditioned group, VEGFR-2 AS significantly increased brain area loss in the cortex, hippocampus, and striatum compared with vehicle or scrambled ODN $\left(*^{* *}<0.01\right.$, ${ }^{\#} p<0.001$ ). In contrast, VEGFR-1 AS did not reduce the protective effects of $24 \mathrm{~h}$ ligation preconditioning. Compared with the $1 \mathrm{~h}$ non-preconditioned group, the $24 \mathrm{~h}$ preconditioned group treated with VEGFR-2 AS had significantly less area loss in the cortex ( $\left.{ }^{\#} p<0.001\right)$, hippocampus ( ${ }^{\#} p<$ $0.001)$, and striatum $\left({ }^{*} p<0.05\right) . n=8-10$ rats per group. Values are means \pm SD. 
gested that VEGF-A/VEGFR-2 signaling leading to CREB activation is the common pathway that mediates the protective effect of OGD preconditioning in neuronal cells as well as in endothelial cells.

CREB phosphorylation was required for the protective effect of OGD preconditioning in neuronal cells and endothelial cells. During phosphorylation at Ser133, CREB facilitates transcriptional activation of the genes containing the CRE motif (Lonze and Ginty, 2002). To determine whether CREB activation is required for the protective effect of OGD preconditioning in neuronal cells and endothelial cells, the cells were transfected with a serine-133 phosphorylation mutant CREB (MCREB133) before OGD preconditioning. Overexpression of MCREB133 in H19-7 cells and in b.End 3 cells showed no significant difference on cell viability compared with vector only (Fig. 9). Cell viability after $24 \mathrm{~h}$ OGD showed that the protective effect of OGD preconditioning was significantly lower in H19-7 cells and b.End3 cells that had been transfected with MCREB133 compared with those transfected with vector before OGD preconditioning. In contrast, transfection with vector alone did not affect the $24 \mathrm{~h}$ OGD cell death in H19-7 cells or b.End 3 cells. These results indicated that CREB phosphorylation was required for OGD preconditioning-induced protection in neuronal cells and endothelial cells.

\section{Discussion}

Our previous study (Lee et al., 2004) showed that CREB activation in vivo is an important event in $24 \mathrm{~h}$ carotid-artery ligation-induced neuroprotection against $\mathrm{HI}$ in the neonatal brain. Our present study extends these observations and provides evidence for the first time that ligation preconditioning upregulated VEGFA/VEGFR-2 in vascular endothelial cells and neurons, which provides protection against $\mathrm{HI}$ injury by phosphorylating CREB. We found that CREB phosphorylation and VEGF-A and VEGFR-2, but not VEGFR-1, expression had increased and colocalized in vascular endothelial cells and neurons in the cerebral cortex $24 \mathrm{~h}$ after ligation. We also found that VEGF-A and VEGFR-2, but not VEGFR-1, were necessary for CREB activation and the protective effects of the $24 \mathrm{~h}$ ligation preconditioning in vivo. Additional in vitro study demonstrated that OGD preconditioning protected $\mathrm{H} 19-7$ neuronal cells and b.End3 cerebral vascular endothelial cells against OGD cell death and that VEGF-A/VEGFR-2 signaling through CREB phosphorylation was required for the protective effect of OGD preconditioning in H19-7 cells as well as in b.End3

B
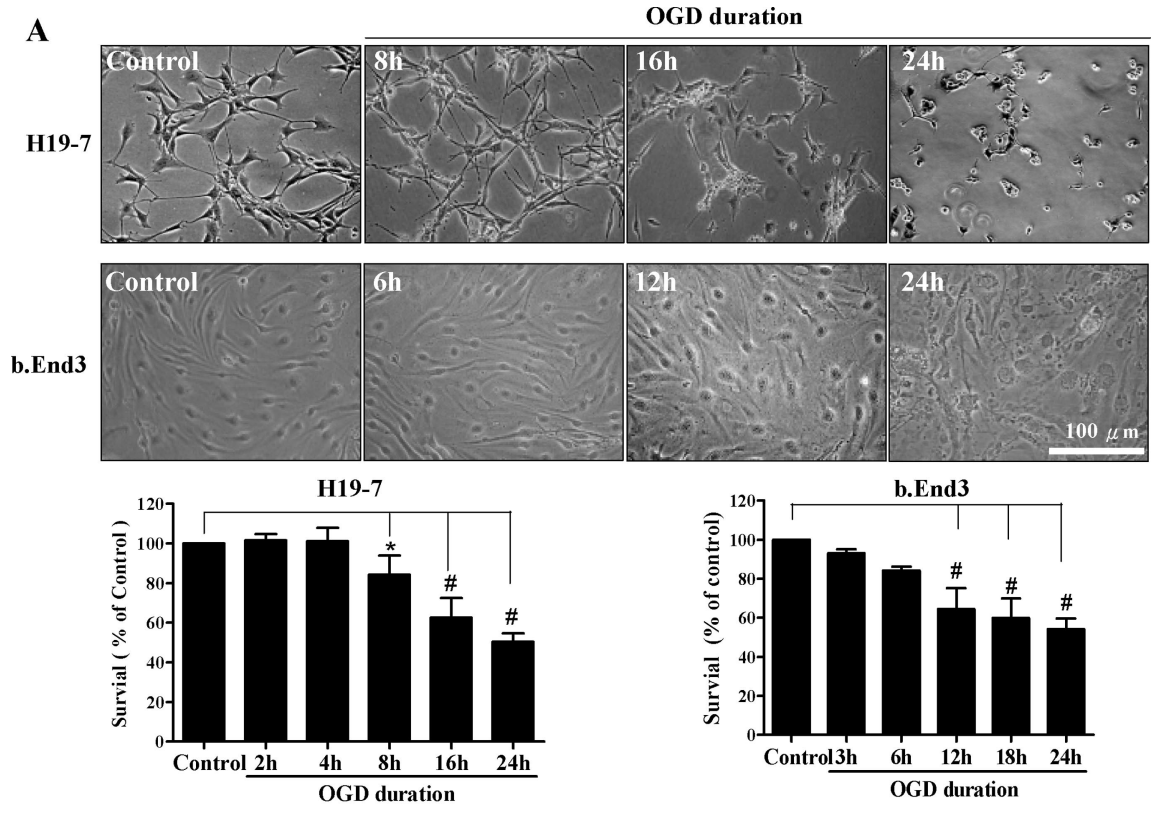

OGD
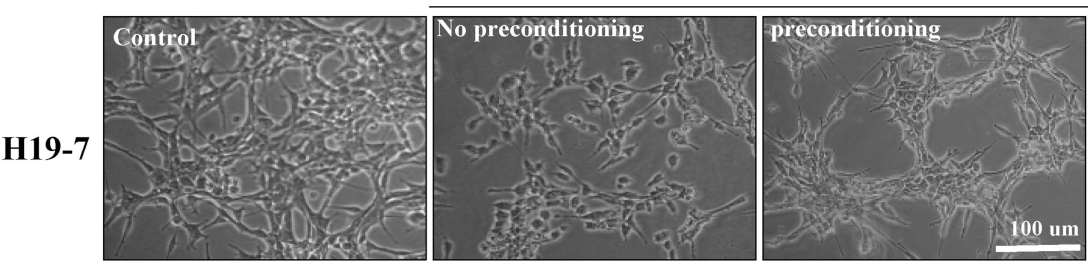

OGD
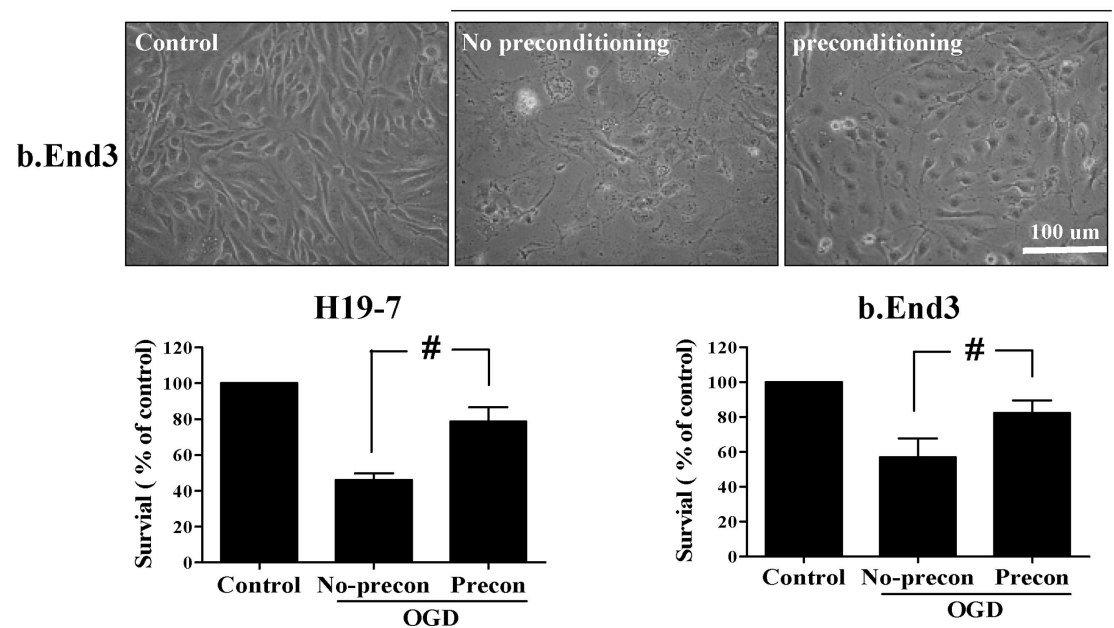

b.End3

Figure 6. $O G D$ preconditioning protected against $O G D$ cell death in immortalized $\mathrm{H} 19-7$ neuronal cells and b. End3 cerebral vascular endothelial cells. The H19-7 cells and b.End3 cells were, respectively, exposed to different durations of OGD, and cell viability was quantitatively assessed using XTT $24 \mathrm{~h}$ after OGD. $A$, Top, Phase-contrast photomicrographs of the effects of different OGD durations on H19-7 cells and b. End3 cells. Bottom, Cell viability decreased progressively in H19-7 cells and b. End 3 cells as the duration of $O G D$ increased up to $24 \mathrm{~h}$, with $\sim 50 \%$ of the $\mathrm{H} 19-7$ cells surviving and $\sim 60 \%$ of the b. End 3 cells surviving. ${ }^{*} p<0.05$, ${ }^{\#} p<0.001$ compared with controls. The cell viability of the control group without $0 G D$ was defined as $100 \%$. Values are means \pm SD from five independent experiments for each time point. $\boldsymbol{B}$, Five hour OGD preconditioning $24 \mathrm{~h}$ before $24 \mathrm{~h} 0 \mathrm{GD}$ significantly increased cell viability from 45 to $75 \%$ in $\mathrm{H} 19-7$ cells and from 58 to $80 \%$ in b. End3 cells. " $p<0.001$ comparison between preconditioned and non-preconditioned cells. Values are means \pm SD from four independent experiments.

cells. Together, both in vivo and in vitro evidence shows that the VEGF-A/VEGFR-2 signaling that leads to CREB phosphorylation is a critical and shared pathway for the preconditioningmediated survival in both neurons and vascular endothelial cells.

Injury to the adult rat brain upregulates VEGF-A expression 
H19-7
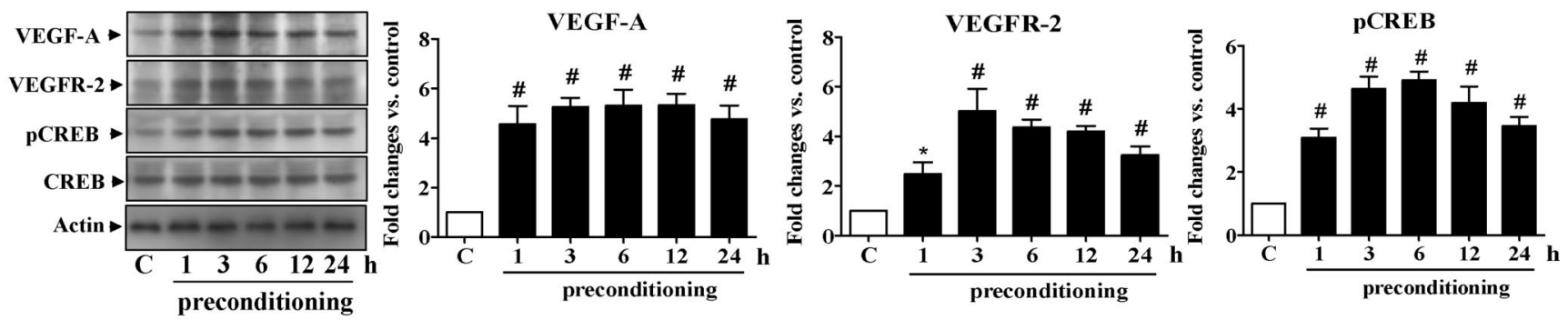

b.End 3


Figure 7. OGD preconditioning upregulated VEGF-A, VEGFR-2, and pCREB expression in H19-7 cells and b.End3 cells. Western blots and densitometric analysis showed that VEGF-A levels were significantly higher at $1 \mathrm{~h}$ and continued to rise for $24 \mathrm{~h}$ after $0 \mathrm{GD}$ preconditioning in the $\mathrm{H} 19-7 \mathrm{cells}$ and $\mathrm{b}$.End 3 cells. The VEGFR-2 levels were higher $1 \mathrm{~h}$ after $0 \mathrm{GD}$ preconditioning in the $\mathrm{H} 19-7 \mathrm{cells}$ and b.End 3 cells, and the higher levels were sustained for $24 \mathrm{~h}$ in $\mathrm{H} 19-7$ cells and for $12 \mathrm{~h}$ in b.End 3 cells after preconditioning. $\mathrm{pCREB}$ levels were higher $1 \mathrm{~h}$ after preconditioning in $\mathrm{H} 19-7 \mathrm{cells}$ and $3 \mathrm{~h}$ after preconditioning in b.End3 cells, and the increased $p$ CREB levels persisted for at least $24 \mathrm{~h}$ after preconditioning in both types of cells. ${ }^{*} p<0.05,{ }^{* *} p<0.01$, ${ }^{*} p<0.001$ compared with non-preconditioned controls. Values are means \pm SD from three independent experiments.

in the penumbra of the infarct; this upregulation recapitulates certain developmental events that lead to physiological repair (Storkebaum et al., 2004). VEGF-A administration improved neural recovery after cerebral ischemia (Zhang et al., 2000; Sun et al., 2003), and, when VEGF was overexpressed in neurons, it delayed neurodegeneration in amyotrophic lateral sclerosis mice (Wang et al., 2007). The antisense knockdown of VEGF-A after ischemic stroke enlarged the infarct volume (Yang et al., 2002), and deleting the hypoxia-response element in the VEGF promoter in "knock-in" mice caused motor-neuron degeneration (Oosthuyse et al., 2001). These studies on the adult rat brain provide evidence that VEGF-A directly protects neurons. Both VEGF-A and VEGFR are more highly expressed in the vessels and neurons of the developing than the adult brain (Ogunshola et al., 2000; Brockington et al., 2004). Microarray analysis of the effect of hypoxic preconditioning in neonatal rats showed that many vascular genes related to the regulation of angiogenesis and vasoregulation had been upregulated in the cerebral cortex (Gustavsson et al., 2007). Here, we found that VEGF-A expression in neurons and vascular endothelial cells had significantly increased after ligation preconditioning in vivo and OGD preconditioning in vitro. The result of VEGF-A antisense ODN in vivo showed that increased VEGF-A expression was closely linked to the protective effect of $24 \mathrm{~h}$ ligation preconditioning. Furthermore, our in vitro study showed that VEGF-A was upregulated and also required for the protective effect of OGD preconditioning in H19-7 cells and b.End 3 cells. Our in vivo and in vitro preconditioning findings not only are compatible with the reports that VEGF-A mediated the protective effect of hypoxic preconditioning in neurons (Wick et al., 2002; Laudenbach et al., 2007) but also further characterize the shared protective pathway of VEGF-A, leading to CREB activation in neurons and endothelial cells. In addition, VEGFR-1 and VEGFR-2 expression was also upregulated in neurons and endothelial cells in the penumbra after ischemia (Brockington et al., 2004). In vitro studies showed that VEGFR-2 is crucial for the survival of neuronal cells and endothelial cells (Rosenstein et al., 2003; Storkebaum et al., 2004). The correlation of the temporal and spatial expressions of VEGFR-2 and VEGF-A suggests that this ligand-receptor signaling system has a major function during brain development (Millauer et al., 1993). We found that VEGFR-2 was predominantly upregulated and colocalized with VEGF-A in vessels and neurons after preconditioning and that blockading VEGF-A decreased VEGFR-2 expression and concomitantly reduced the protective effect of ligation preconditioning. The particular constellation present after ligation preconditioning in vivo and OGD preconditioning in vitro appears to highlight the importance of the protective effect of VEGF-A/ VEGFR-2 signaling in neuronal cells and endothelial cells.

Localized within the nucleus, the transcription factor CREB is crucial for stimulus-transcription coupling: the transmission of events that occur at cell membranes into alterations in gene expression and ultimately in neuronal function. A number of studies (Mabuchi et al., 2001; Lonze and Ginty, 2002; Hara et al., 2003; Lee et al., 2004) have shown that phosphorylation of CREB on the transcriptional regulatory site Ser 133 in neurons is an important mechanism in ischemic tolerance. Differential susceptibility to the hypoxia-induced death of neurons correlates well with the ability to sustain CREB phosphorylation in neurons (Mabuchi et al., 2001). In the hippocampus, temporary global ischemia induces pCREB that is transient in the hippocampus CA1 neurons but prolonged in dentate gyrus neurons (Walton and Dragunow, 2000). Whereas CA1 neurons are drastically depleted after the ischemic insult, dentate gyrus neurons are substantially spared. Although many preconditioning studies have focused on the prosurvival role of CREB activation in the induction of ischemic tolerance in neurons (Mabuchi et al., 2001; Hara et al., 2003; Lee et al., 2004; Meller et al., 2005), very few examine whether CREB activation is also involved in the ischemic tolerance of cerebral 
vascular endothelial cells. Given the potent impact of CREB on neurons, CREB would be expected to have pleiotropic effects on cerebral endothelial cells. Our data showed that increased CREB activation was seen in neurons and vascular endothelial cells and that there was sustained CREB activation 12-24 $\mathrm{h}$ after ligation preconditioning in the neonatal rat brain. Although sustained CREB phosphorylation in neurons correlates with the increased survival of neurons, our study is the first to extend the prosurvival role of preconditioning-induced CREB activation from neurons to cerebral vascular endothelial cells. Our findings suggest that preconditioning protects neurons and vascular endothelial cells, and the activation of CREB-dependent survival programs in response to preconditioning is a critical form of defense in both neurons and endothelial cells in the nervous system. More studies are needed to investigate how long and to what level the induction of this increased CREB activation continues, especially because the ligation-preconditioned group showed complete neuroprotection $23 \mathrm{~d}$ after $\mathrm{HI}$ in all 50 rats examined. It will also be interesting to know whether there are differential effects of CREB in vascular endothelial cells (e.g., angiogenesis) versus neurons.

In neurons, a wide range of extracellular stimuli are capable of activating CREB. Neurotrophins and neurotransmitters are well known to act on membrane receptors (e.g., G-protein-coupled receptors and NMDA receptors) and exert their influence via multiple signaling cascades that converge and lead to CREB phosphorylation (Finkbeiner, 2000; Lonze and Ginty, 2002). VEGF-A has potent growth and survival effects on neurons and vascular elements in the nervous system. Nonetheless, the possible role of VEGF-A in CREB activation in neurons and vascular endothelial cells has been little investigated. Although VEGF-A was reported to activate CREB by signaling through VEGFR-2 in human umbilical vascular endothelial cells (Mayo et al., 2001), the function and relationship of VEGF-A and CREB in cerebral vascular endothelial cells and neurons remains unknown. Here, we showed that upregulated VEGF-A and VEGFR-2 expression after ligation preconditioning colocalized with $\mathrm{PCREB}$ in neurons and endothelial cells. Blockading VEGF-A and VEGFR-2 instead of VEGFR-1 decreased pCREB expression and concomitantly reduced the protective effect of ligation preconditioning. These findings suggest that $24 \mathrm{~h}$ artery ligation preconditioning in the neonatal brain activates CREB by signaling through VEGF-A/ VEGFR-2. Additional in vitro study showed that the protective effect of OGD preconditioning in H19-7 cells and b.End3 cells required the same $\mathrm{CREB}$ activation mechanism. Inhibiting VEGF-A or VEGFR-2 decreased CREB activation and significantly reduced the protective effect of OGD preconditioning in
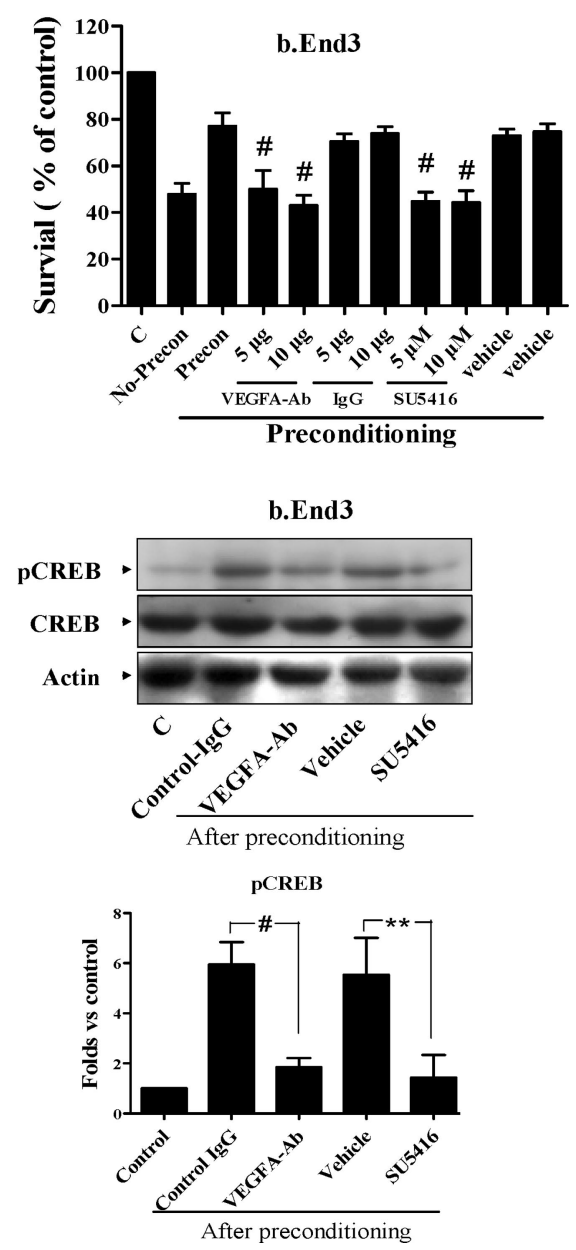

H19-7

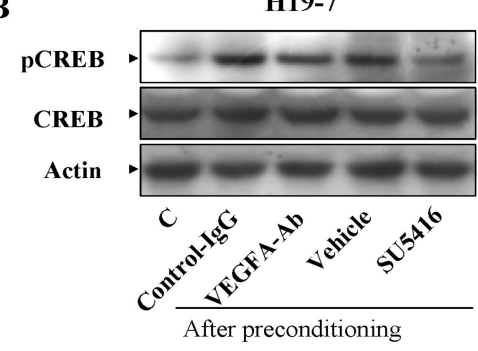

pCREB

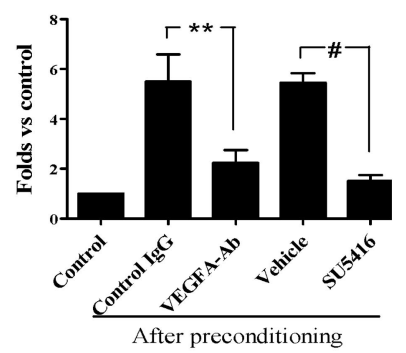

After preconditioning

Figure 8. VEGF-A/VEGFR-2 signaling was required for CREB activation and the protective effect of OGD preconditioning in H19-7 cells and $b$.End 3 cells. The cells were pretreated with a neutralizing antibody against VEGF-A (VEGF-A Ab) or control-lgG, or a VEGFR-2 inhibitor (SU5416) or its vehicle, 5 min before 5 h OGD preconditioning, followed by 24 h 0GD. A, Compared with (1) cenditioning in H19-7 cells and b. End3 cells. Pretreating the cells with SU5416 (5 or $10 \mu \mathrm{m}$ ) also significantly reduced the protective effect of OGD preconditioning in both types of cells. ${ }^{*} p<0.001$ for the comparison between VEGF-A Ab and IgG and for

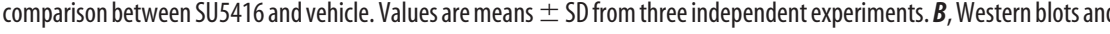
nificantly lower in cells pretreated with VEGF-A Ab (10 $\mu \mathrm{g} / \mathrm{ml})$ or SU5416 (5 $\mu \mathrm{m})$ before OGD preconditioning. ${ }^{* *} p<0.01$ ${ }^{\#} p<0.001$ for the comparison between VEGF-A Ab and IgG and for the comparison between SU5416 and vehicle. Values are means \pm SD from three independent experiments.

H19-7 cells and b.End3 cells. Our findings showed that VEGF-A upregulated by preconditioning acted on VEGFR-2 to induce CREB activation in both neurons and vascular endothelial cells. Therefore, our study is the first to show that preconditioninginduced VEGF-A may be one of the upstream inducers for CREB activation and that CREB activation is critical in VEGF-Amediated survival signals in neurons and vascular endothelial cells during preconditioning. Although there are reports on the protective mechanisms of VEGF-A on neurons and endothelial cells, our study is the first to show that VEGF-A/VEGFR-2 induced by preconditioning protect neurons and vascular endothelial cells through CREB activation. The preconditioned group treated with VEGF-A AS or VEGFR-2 AS still had significantly lower levels of brain damage than did the non-preconditioned group treated with vehicle. Possible reasons accounting for the neuroprotection still seen in the preconditioned animals after being pretreated with VEGF-A/VEGFR2-AS include the follow- 

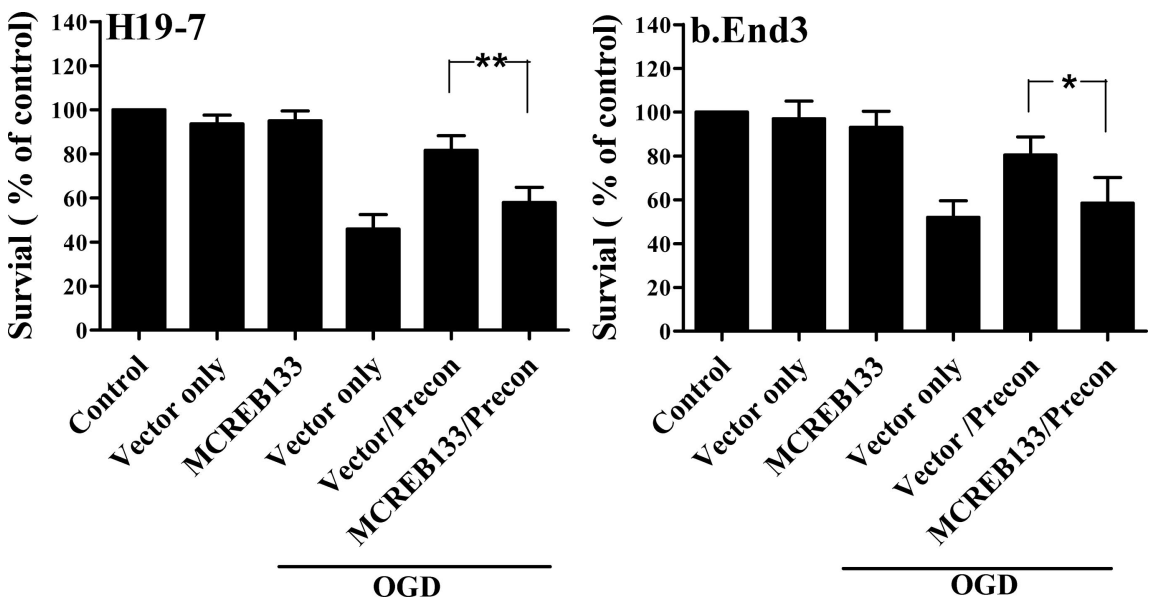

Figure 9. CREB phosphorylation was required for the protective effect of OGD preconditioning in $\mathrm{H} 19-7$ cells and b.End3 cells. The cells were transfected with a serine-133 phosphorylation mutant CREB (MCREB133) or empty vector $36 \mathrm{~h}$ before $5 \mathrm{~h}$ OGD preconditioning. The cells were later treated with $24 \mathrm{~h}$ 0GD. Overexpression of MCREB 133 in H19-7 cells and in b. End 3 cells had no significant effect on cell viability compared with vector only. Cell viability after $24 \mathrm{~h} 0 \mathrm{GD}$ showed that the protective effect of $0 \mathrm{GD}$ preconditioning was significantly lower in $\mathrm{H} 19-7$ cells and $b$. End 3 cells that had been transfected with MCREB 133 compared with those transfected with vector only before $0 \mathrm{GD}$ preconditioning $\left({ }^{*} p<0.05,{ }^{* *} p<0.01\right.$, for the comparison between preconditioned cells pretreated with MCREB133 and those pretreated with vector only). Values are means \pm SD from three independent experiments.

ing: (1) the effect of intracerebroventricular infusion of VEGF-A AS or VEGFR-2 AS on reducing the expression of VEGF-A or VEGFR-2 in the cerebral hemisphere may not be as extended and effective as the effect of $24 \mathrm{~h}$ ligation preconditioning on upregulating VEGF-A and VEGFR-2 levels; (2) other signaling mechanisms, such as nitric oxide, NMDA receptor, and nuclear factor- $\kappa \mathrm{B}$ (Chang and Huang, 2006; Gidday, 2006), may also be involved in the protective effect of $24 \mathrm{~h}$ ligation preconditioning.

An in vitro study (Ogunshola et al., 2002) showed that VEGF expressed by murine embryonic day 15 neurons is capable of promoting paracrine endothelial survival and autocrine and paracrine neuronal survival through VEGFR-2 signaling. Our study showed that ligation preconditioning increased CREB phosphorylation on the VEGFR-2 ${ }^{+}$vessels and neurons. Because VEGF-A was also upregulated in neuronal cells and endothelial cells after both ligation preconditioning and OGD preconditioning, coinciding expression of VEGF-A, VEGFR-2, and pCREB may result in the generation of autocrine and paracrine loops that support neuroprotection and vasoprotection against HI (Lee et al., 2007).

Neurons and vascular endothelial cells are highly sensitive to ischemic injury. Accordingly, optimal treatments for $\mathrm{HI}$ brain injury should target not only neurons but also cerebral blood vessels. Evidence indicates that preserving neuronal and vascular functions is essential for ischemic tolerance (Kunz et al., 2007) and that combining neuroprotection and vasoprotection may be a valuable strategy for treating HI brain injury. The common VEGF-A mechanisms involved in wiring the neural and vascular networks during development are potential therapeutic targets for neuroprotection and vasoprotection (Carmeliet and TessierLavigne, 2005). Our study provides evidences that preconditioning in the developing brain recapitulates the shared developmental cellular events of vessels and neurons. In the present study, we hypothesize that, in the preconditioning of developing brain, VEGF-A/VEGFR-2 serves its protective function through CREB activation: promoting the survival of neurons and endothelial cells against $\mathrm{HI}$ injury through autocrine and paracrine loops. Our study also suggests that drugs that mimic the beneficial ef- fects of preconditioning by activating through VEGFR-2/CREB signaling on both neurons and endothelial cells may provide powerful therapeutic strategies for treating $\mathrm{HI}$ injury.

Hypoxic preconditioning increases vascular density and attenuates the decrease of cerebral blood flow during the subsequent HI injury (Gustavsson et al., 2007). Here, the effect of ligation preconditioning on vascular function remains unclear. All of the $24 \mathrm{~h}$ ligation (preconditioned) group rats had complete neuroprotection, whereas $90 \%$ of the $1 \mathrm{~h}$ ligation (non-preconditioned) group rats had various degrees of damage. Therefore, in addition to the protective signaling events in neurons and endothelial cells induced by $24 \mathrm{~h}$ ligation preconditioning, more studies are needed to address whether vascular events, such as angiogenesis, cerebral blood flow, and the intactness of the blood-brain barrier, are involved in the protective effect of $24 \mathrm{~h}$ ligation preconditioning in the neonatal brain and whether knockdown of the endothelial VEGF system or CREB has functional consequences for angiogenesis or the intactness of the blood-brain barrier.

\section{References}

Andjelkovic AV, Stamatovic SM, Keep RF (2003) The protective effects of preconditioning on cerebral endothelial cells in vitro. J Cereb Blood Flow Metab 23:1348-1355.

Beauchamp P, Richard V, Tamion F, Lallemand F, Lebreton JP, Vaudry H, Daveau M, Thuillez C (1999) Protective effects of preconditioning in cultured rat endothelial cells: effects on neutrophil adhesion and expression of ICAM-1 after anoxia and reoxygenation. Circulation 100:541-546.

Brockington A, Lewis C, Wharton S, Shaw PJ (2004) Vascular endothelial growth factor and the nervous system. Neuropathol Appl Neurobiol 30:427-446.

Cao L, Jiao X, Zuzga DS, Liu Y, Fong DM, Young D, During MJ (2004) VEGF links hippocampal activity with neurogenesis, learning and memory. Nat Genet 36:827-835.

Carmeliet P, Tessier-Lavigne M (2005) Common mechanisms of nerve and blood vessel wiring. Nature 436:193-200.

Chang S, Jiang X, Zhao C, Lee C, Ferriero DM (2008) Exogenous low dose hydrogen peroxide increases hypoxia-inducible factor-1alpha protein expression and induces preconditioning protection against ischemia in primary cortical neurons. Neurosci Lett 441:134-138.

Chang YC, Huang CC (2006) Perinatal brain injury and regulation of transcription. Curr Opin Neurol 19:141-147.

Ferrara N, Gerber HP, LeCouter J (2003) The biology of VEGF and its receptors. Nat Med 9:669-676.

Ferriero DM (2004) Neonatal brain injury. N Engl J Med 351:1985-1995.

Finkbeiner S (2000) CREB couples neurotrophin signals to survival messages. Neuron 25:11-14.

Gidday JM (2006) Cerebral preconditioning and ischaemic tolerance. Nat Rev Neurosci 7:437-448.

Greenberg DA, Jin K (2005) From angiogenesis to neuropathology. Nature 438:954-959.

Gustavsson M, Mallard C, Vannucci SJ, Wilson MA, Johnston MV, Hagberg $\mathrm{H}$ (2007) Vascular response to hypoxic preconditioning in the immature brain. J Cereb Blood Flow Metab 27:928-938.

Hara T, Hamada J, Yano S, Morioka M, Kai Y, Ushio Y (2003) CREB is required for acquisition of ischemic tolerance in gerbil hippocampal CA1 region. J Neurochem 86:805-814.

Hillion JA, Li Y, Maric D, Takanohashi A, Klimanis D, Barker JL, Hallenbeck 
JM (2006) Involvement of Akt in preconditioning-induced tolerance to ischemia in PC12 cells. J Cereb Blood Flow Metab 26:1323-1331.

Hoyte LC, Papadakis M, Barber PA, Buchan AM (2006) Improved regional cerebral blood flow is important for the protection seen in a mouse model of late phase ischemic preconditioning. Brain Res 1121:231-237.

Huang CC, Wang ST, Chang YC, Lin KP, Wu PL (1999) Measurement of the urinary lactate:creatinine ratio for the early identification of newborn infants at risk for hypoxic-ischemic encephalopathy. $\mathrm{N}$ Engl J Med 341:328-335.

Kunz A, Park L, Abe T, Gallo EF, Anrather J, Zhou P, Iadecola C (2007) Neurovascular protection by ischemic tolerance: role of nitric oxide and reactive oxygen species. J Neurosci 27:7083-7093.

Laudenbach V, Fontaine RH, Medja F, Carmeliet P, Hicklin DJ, Gallego J, Leroux P, Marret S, Gressens P (2007) Neonatal hypoxic preconditioning involves vascular endothelial growth factor. Neurobiol Dis 26:243-252.

Lee HT, Chang YC, Wang LY, Wang ST, Huang CC, Ho CJ (2004) cAMP response element-binding protein activation in ligation preconditioning in neonatal brain. Ann Neurol 56:611-623.

Lee S, Chen TT, Barber CL, Jordan MC, Murdock J, Desai S, Ferrara N, Nagy A, Roos KP, Iruela-Arispe ML (2007) Autocrine VEGF signaling is required for vascular homeostasis. Cell 130:691-703.

Lonze BE, Ginty DD (2002) Function and regulation of CREB family transcription factors in the nervous system. Neuron 35:605-623.

Mabuchi T, Kitagawa K, Kuwabara K, Takasawa K, Ohtsuki T, Xia Z, Storm D, Yanagihara T, Hori M, Matsumoto M (2001) Phosphorylation of cAMP response element-binding protein in hippocampal neurons as a protective response after exposure to glutamate in vitro and ischemia in vivo. J Neurosci 21:9204-9213.

Mayo LD, Kessler KM, Pincheira R, Warren RS, Donner DB (2001) Vascular endothelial cell growth factor activates CRE-binding protein by signaling through the KDR receptor tyrosine kinase. J Biol Chem 276:25184-25189.

Meller R, Minami M, Cameron JA, Impey S, Chen D, Lan JQ, Henshall DC, Simon RP (2005) CREB-mediated Bcl-2 protein expression after ischemic preconditioning. J Cereb Blood Flow Metab 25:234-246.

Millauer B, Wizigmann-Voos S, Schnürch H, Martinez R, Møller NP, Risau W, Ullrich A (1993) High affinity VEGF binding and developmental expression suggest Flk-1 as a major regulator of vasculogenesis and angiogenesis. Cell 72:835-846.

Ogunshola OO, Stewart WB, Mihalcik V, Solli T, Madri JA, Ment LR (2000) Neuronal VEGF expression correlates with angiogenesis in postnatal developing rat brain. Brain Res Dev Brain Res 119:139-153.

Ogunshola OO, Antic A, Donoghue MJ, Fan SY, Kim H, Stewart WB, Madri JA, Ment LR (2002) Paracrine and autocrine functions of neuronal vascular endothelial growth factor (VEGF) in the central nervous system. J Biol Chem 277:11410-11415.

Oosthuyse B, Moons L, Storkebaum E, Beck H, Nuyens D, Brusselmans K,
Van Dorpe J, Hellings P, Gorselink M, Heymans S, Theilmeier G, Dewerchin M, Laudenbach V, Vermylen P, Raat H, Acker T, Vleminckx V, Van Den Bosch L, Cashman N, Fujisawa H, et al. (2001) Deletion of the hypoxia-response element in the vascular endothelial growth factor promoter causes motor neuron degeneration. Nat Genet 28:131-138.

Paxinos G, Watson C (1986) The rat brain in stereotaxic coordinates, Ed 2. San Diego: Academic.

Ratan RR (2004) cAMP response element binding protein family transcription factors: the Holy Grail of neurological therapeutics? Ann Neurol 56:607-608.

Rosenstein JM, Mani N, Khaibullina A, Krum JM (2003) Neurotrophic effects of vascular endothelial growth factor on organotypic cortical explants and primary cortical neurons. J Neurosci 23:11036-11044.

Storkebaum E, Lambrechts D, Carmeliet P (2004) VEGF: once regarded as a specific angiogenic factor, now implicated in neuroprotection. Bioessays 26:943-954.

Sun Y, Jin K, Xie L, Childs J, Mao XO, Logvinova A, Greenberg DA (2003) VEGF-induced neuroprotection, neurogenesis, and angiogenesis after focal cerebral ischemia. J Clin Invest 111:1843-1851.

Sung JY, Shin SW, Ahn YS, Chung KC (2001) Basic fibroblast growth factorinduced activation of novel CREB kinase during the differentiation of immortalized hippocampal cells. J Biol Chem 276:13858-13866.

Vannucci RC, Towfighi J, Heitjan DF, Brucklacher RM (1995) Carbon dioxide protects the perinatal brain from hypoxic-ischemic damage: an experimental study in the immature rat. Pediatrics 95:868-874.

Walton MR, Dragunow I (2000) Is CREB a key to neuronal survival? Trends Neurosci 23:48-53.

Wang Y, Mao XO, Xie L, Banwait S, Marti HH, Greenberg DA, Jin K (2007) Vascular endothelial growth factor overexpression delays neurodegeneration and prolongs survival in amyotrophic lateral sclerosis mice. J Neurosci 27:304-307.

Wick A, Wick W, Waltenberger J, Weller M, Dichgans J, Schulz JB (2002) Neuroprotection by hypoxic preconditioning requires sequential activation of vascular endothelial growth factor receptor and Akt. J Neurosci 22:6401-6407.

Yang ZJ, Bao WL, Qiu MH, Zhang LM, Lu SD, Huang YL, Sun FY (2002) Role of vascular endothelial growth factor in neuronal DNA damage and repair in rat brain following a transient cerebral ischemia. J Neurosci Res 70:140-149.

Zacchigna S, Lambrechts D, Carmeliet P (2008) Neurovascular signalling defects in neurodegeneration. Nat Rev Neurosci 9:169-181.

Zhang Y, Park TS, Gidday JM (2007) Hypoxic preconditioning protects human brain endothelium from ischemic apoptosis by Akt-dependent survivin activation. Am J Physiol Heart Circ Physiol 292:H2573-H2581.

Zhang ZG, Zhang L, Jiang Q, Zhang R, Davies K, Powers C, Bruggen N, Chopp M (2000) VEGF enhances angiogenesis and promotes bloodbrain barrier leakage in the ischemic brain. J Clin Invest 106:829-838. 